\title{
The Importance of Communication within Organizations: A Research on Two Hotels in Uttarakhand
}

\author{
${ }^{1}$ Dr. Shipra Agarwal, ${ }^{2}$ Mr. Ashish Garg
}

\begin{abstract}
As a feature of socially defined people, everyone is in communication with the others in the social context. Whatever the content is, individuals should exchange and share thoughts, news, in other words they should communicate. In this regard, especially in organizations where formal and informal communication exists, "communication within organization" plays a vital role in structuring the organizational activities, objectives, company policies and strategies.
\end{abstract}

Key Words: Communication, information sources, interaction between employees and managers, five-star hotels.

\section{Introduction}

Communication can be defined as the exchange of an information, thought and emotion between individusals of groups; in other words, communication plays a fundamental role in balancing individual and organizational objectives. Communication is the activity of conveying information. Communication has been derived from the Latin word "communis", meaning to share. Communication requires a sender, a message, and an intended recipient, although the receiver need not be present or aware of the sender's intent to communicate at the time of communication; thus communication can occur across vast distances in time and space. Communication requires that the communicating parties share an area of communicative commonality. The communication process is complete once the receiver has understood the message of the sender. Feedback is critical to effective communication between parties.

\section{Types of communication}

Communication within organizations is classified into two groups as formal and informal. The types of formal communication are "up to down", "down to up", "horizontal" and "cross" communication.

Nonverbal communication describes the process of conveying meaning in the form of non-word messages. Research shows that the majority of our communication is non verbal, also known as body language. Some of non verbal communication includes chronemics, haptics, gesture, body language or posture; facial expression and eye contact, object communication such as clothing, hairstyles, architecture, symbols infographics, and tone of voice as well as through an aggregate of the above.

Speech also contains nonverbal elements known as paralanguage. These include voice lesson quality, emotion and speaking style as well as prosodic features such as rhythm, intonation and stress. Likewise, written texts include nonverbal elements such as handwriting style, spatial arrangement of words and the use of emoticons to convey emotional expressions in pictorial form

\section{Oral communication}

Oral communication, while primarily referring to spoken verbal communication, can also employ visual aids and non-verbal elements to support the conveyance of meaning. Oral communication includes speeches, presentations, discussions, and aspects of interpersonal communication. As a type of face-to-face communication, body language and voice tonality play a significant role, and may have a greater impact upon the listener than informational content. This type of communication also garners immediate feedback.

\section{Barriers to effective human communication}

Communication is the key factor in the success of any organization. When it comes to effective communication, there are certain barriers that every organization faces. People often feel that communication is as easy and simple as it sounds. No doubt, but what makes it complex, difficult and frustrating are the barriers that come in its way. Some of these barriers are mentioned below.

Barriers to successful communication include message overload (when a person receives too many messages at the same time), and message complexity.

Physical barriers: Physical barriers are often due to the nature of the environment. Thus, for example, the natural barrier which exists, if staff are located in different buildings or on different sites. Likewise, poor or 
outdated equipment, particularly the failure of management to introduce new technology, may also cause problems. Staff shortages are another factor which frequently causes communication difficulties for an organization. Whilst distractions like background noise, poor lighting or an environment which is too hot or cold can all affect people's morale and concentration, which in turn interfere with effective communication.

System design: System design faults refer to problems with the structures or systems in place in an organization. Examples might include an organizational structure which is unclear and therefore makes it confusing to know who to communicate with. Other examples could be inefficient or inappropriate information systems, a lack of supervision or training, and a lack of clarity in roles and responsibilities which can lead to staff being uncertain about what is expected of them.

Attitudinal barriers: Attitudinal barriers come about as a result of problems with staff in an organisation. These may be brought about, for example, by such factors as poor management, lack of consultation with employees, personality conflicts which can result in people delaying or refusing to communicate, the personal attitudes of individual employees which may be due to lack of motivation or dissatisfaction at work, brought about by insufficient training to enable them to carry out particular tasks, or just resistance to change due to entrenched attitudes and ideas.

Ambiguity of Words/Phrases: Words sounding the same but having different meaning can convey a different meaning altogether. Hence the communicator must ensure that the receiver receives the same meaning. It would be better if such words can be avoided by using alternatives.

Individual linguistic ability is also important. The use of difficult or inappropriate words in communication can prevent people from understanding the message. Poorly explained or misunderstood messages can also result in confusion. We can all think of situations where we have listened to something explained which we just could not grasp. Interestingly, however, research in communication has shown that confusion can lend legitimacy to research when persuasion fails.

Physiological barriers: may result from individuals' personal discomfort, caused—for example — by ill health, poor eyesight or hearing difficulties.

Presentation of information: is also important to aid understanding. Simply put, the communicator must consider the audience before making the presentation itself and in cases where it is not possible the presenter can at least try to simplify his/her vocabulary so that majority can understand.

Importance of Effective Communication: No matter how brilliant and invaluable your idea, it is worthless unless you can share it with others. For this reason, effective communication is crucial at every level of an organization. However, the ability to communicate effectively does not come easily to many people, and it is a skill that requires practice.

We begin practicing our communication skills even before we learn to walk. A newborn child communicates by crying, but it slowly learns to mimic its parents' speech. Eventually, the child discovers that certain speech patterns elicit different responses; one of the joys of parenting is trying to decipher the meaning behind certain "words." Does "baaaaaw" mean that the baby wants his ball, his bottle, or his blanket? Slowly, through trial and error, the child learns to manipulate sounds to get what it wants, and as the child develops, this active oral practice leads to more nuanced and fluid conversations. In short, the child learns effective communication. To effectively communicate a complex idea, however, requires skills beyond elementary conversation. There are two golden rules to remember and follow.

Organize thoughts before sharing: One idea often prompts a torrent of others. In order to share your ideas, you must first shape them coherently. Organization is important, because it creates a pattern for your listener, allowing him or her to grasp the larger picture intuitively. This allows the listener to focus on the details of your message, without struggling to understand how you went from Point A to Point B. As a thought experiment, imagine that a colleague has asked you for directions to the airport. Write them down. Your directions will probably look something like:

- Drive west half a mile on Aurora.

- Take a left on Madison.

- At the third light, turn right and follow Dexter for 2-3 miles.

- Get on the interstate, heading south. 
Now, with a pair of scissors, cut each line of instructions into a small strip of paper. Jumble the strips up and arrange them in a completely random order, then give them to your colleague. Even with mixed-up directions, $\mathrm{s} /$ he should have no trouble reaching the airport, right? After all, your directions are complete and accurate. Not a single step is missing. The problem, of course, is that your directions are also completely unorganized, rendering them useless. Your colleague will find it impossible to focus on your message itself, because he or she will struggle to follow your message's structure (or lack thereof).

Communication: Collaborative, not Competitive: Thrusting your idea on others mars the beauty and integrity of conversation. Communication is in some ways like a dance; each partner plays off the other, basing his or her steps on the other person's, while simultaneously maintaining a certain amount of individuality. Communication is a two-way process involving an exchange of ideas. If you try to make it one-way, you prevent this exchange and will eventually frustrate the other person. You may also frustrate yourself, if you read the other person's lack of verbosity as disinterest in the conversation, rather than an inability to get a word in. The hallmark of effective communication is the coherent verbal projection of you ideas, so that your listener receives the message that you intend to send. By observing these two rules, you will reduce miscommunication and misunderstandings.

\section{Aim of the research}

The aim of this research is trying to explain the importance of communication in two 4 star hotels in Dehradun Region. In this respect, communication types, tools, sources, interaction between employees in different levels of hotels are investigated.

\section{Content and methodology of the research}

This paper aims to find out real situation of communication levels. Because of its touristic potential, Dehradun region was selected as a sample. According to Regional Tourism Directory, two 4 star hotels have been included in our research.

The questionnaire consists of 30 questions, all of which are close-ended. In this paper only the important results were shown. Questionnaires were answered by 65 employees consisting of 36 employees from different departments of Hotel $\mathrm{X}$ which is a member of a famous hotels chain and 29 employees from different departments of Hotel Y operating as a single organization. For statistical evaluation, SSPS has been used.

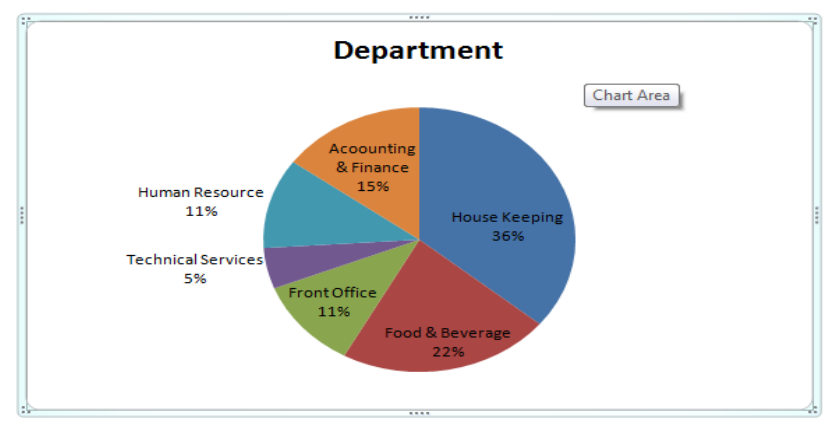

Graphic 1

Chart 1 shows a ranking of departments as stated by the hotels contacted: It can be inferred from the above chart that Housekeeping (36\%), food and beverage (22\%), front office (11\%), human resource (11\%) Accounting \& finance (15\%), technical services (5\%).

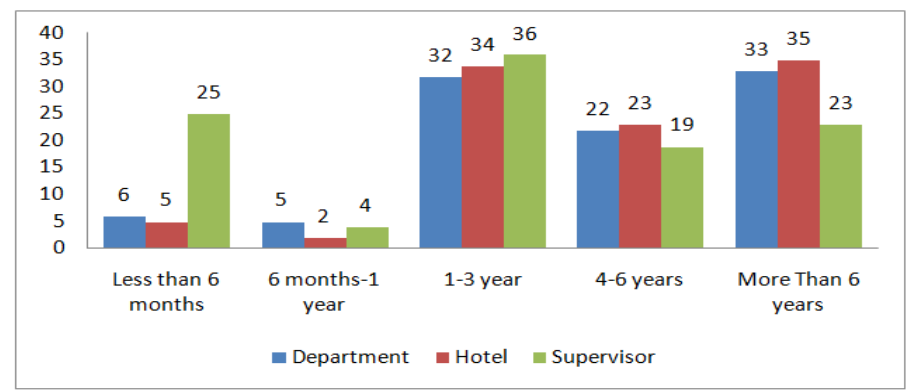

Chart 2 shows a ranking of employee's job experiences: 
- $33 \%$ of the employees are working at the same department for more than 6 years, $22 \%$ of them (for 4-6 years), $32 \%$ of employees (for 1-3 years), $5 \%$ of them are working at the same department(for 6 months1 year), $6 \%$ of them (for less than 6 months)

- $\quad 35 \%$ of employees are working at the same hotel for more than 6 years, $23 \%$ are working (for 4-6 years), $34 \%$ of them (for $1-3$ years), $2 \%$ for (6months- 1 year), $5 \%$ of them (for less than 6 months).

- $\quad 23 \%$ of them (for more than 6 years), $19 \%$ of them (for 4-6 years), $36 \%$ of employees are working with the same supervisors (for 1-3 years), $4 \%$ of them (6 months- 1 year), $25 \%$ of them (for less than 6 months),

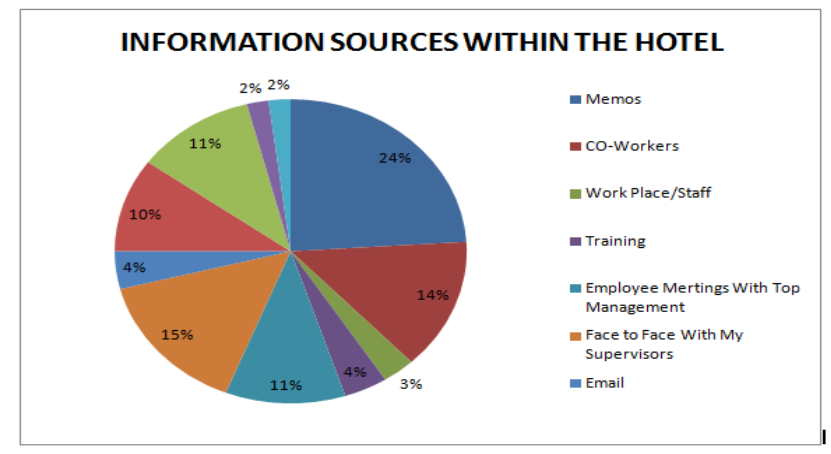

Chart 3 shows a ranking of information sources within the hotel as stated by the hotels contacted: Memos (24\%), supervisors (15\%), coworkers (14\%), employee meetings with top management and documents reported to departments (11\%), bulletin boards (10\%), E-mail and training possibilities (4\%), workplace/staff meetings with boss $(3 \%)$.

This ranking shows a normal communications levels in the sampled hotels. In communication, written communication plays an important role as well as oral communication. At this context the rate of using bulletin boards, workplace staff meetings, E-mail connections can be increased.

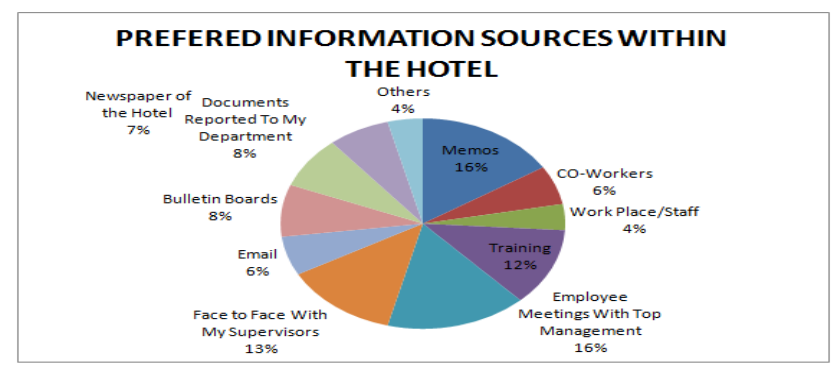

Chart4 shows a ranking of information sources within the hotel in order of employee's preferences: Memos and employee meetings with top management (16\%), supervisors (13\%), training (12\%), Newspaper (7\%), Documents reported to departments (8\%), bulletin boards (8\%), and coworkers $(6 \%)$.

These results again show the importance of written and oral communication within sampled hotels. According to employee's preferences information sources with the top three are memos and employee meetings, supervisors and training.

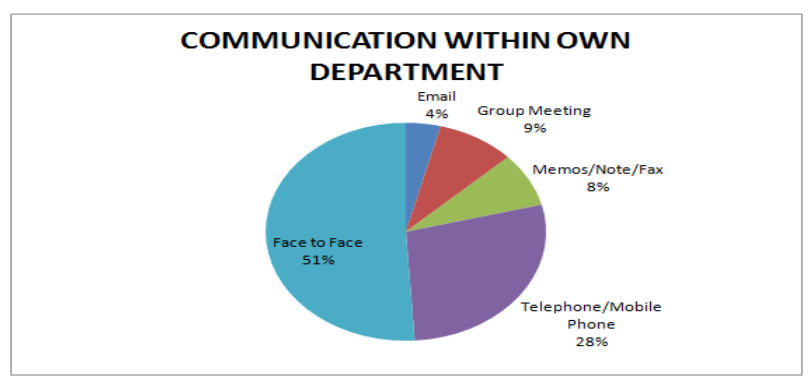

Chart 5 ranks communication within own department with the top three: face to face (51\%), telephone/mobile telephone $(28 \%)$ and group meeting $(9 \%)$. It can be inferred from it that face to face communication is the most trusted way of communication within own department. 


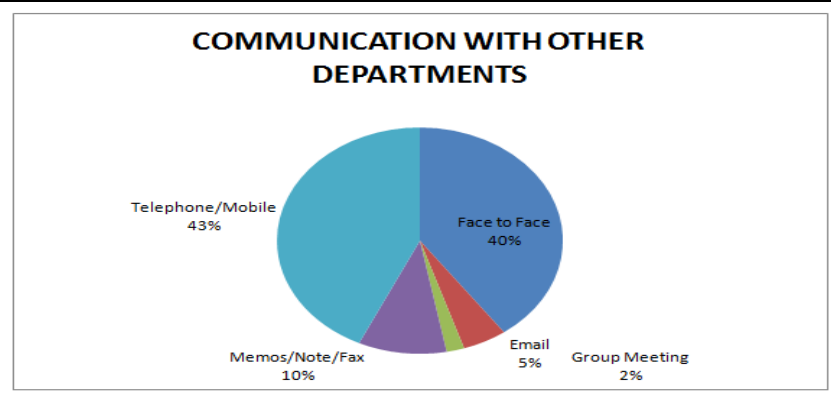

Chart 6 ranks communication with other departments with the top three: telephone/mobile telephone (43\%), face to face $(40 \%)$, and memos/note/fax $(10 \%)$.

It can be inferred from the above chart that when communicated with other department the most preferred way of communication is telephone/mobile. Both in graphic 3 and 4 with little changes in the order, the most important communication tools are nearly the same. With its less importance, E-mail connections are also preferred because of its speed and economic aspects.

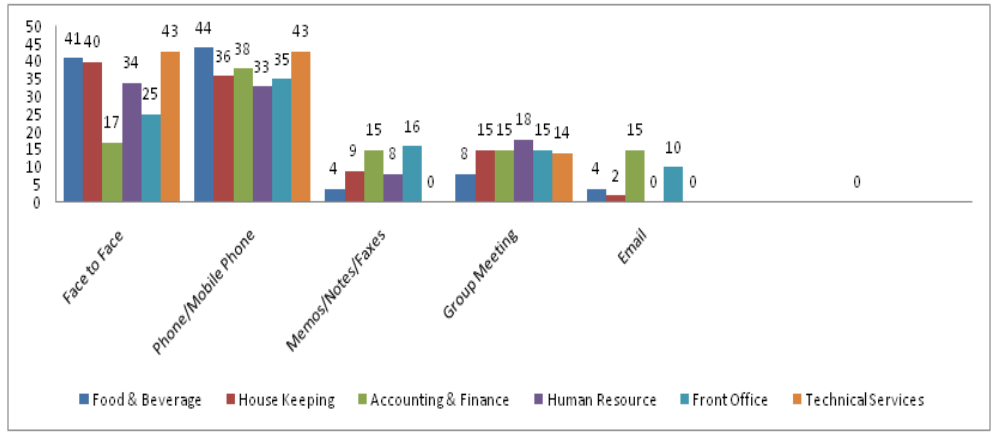

Chart 7 shows a ranking of communication preferences according to departments:

- Food \& Beverage; telephone/mobile phone (44\%), face to face (40\%), group meeting (8\%), memos/note/fax and E-mail (4\%).

- Housekeeping; face to face (41\%), telephone/mobile phone (33\%), group meeting (15\%), memos/note/fax (9\%), E-mail (2\%).

- Accounting \& Finance: telephone/mobile phone (38 \%), face to face, memos/note/fax, group meeting, Email (\%15).

- Human Resources; face to face and telephone/mobile phone (36\%), group meeting (18 \%), memos/note/fax (9\%).

- Front Office; telephone/mobile phone (35\%), face to face (25\%), memos/note/fax and group meeting (15\%), E-mail (\%10).

Technical Services; face to face and telephone/mobile phone (43\%), group meeting (\%14).

"How often do you communicate with your manager?"

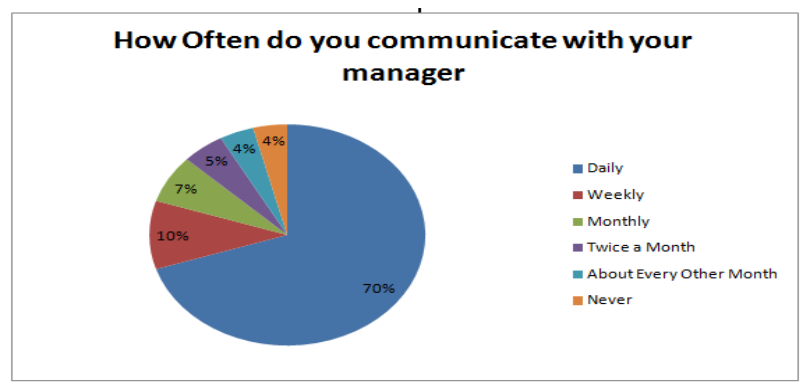

The frequency of communication with the managers according to ranking are: daily (70\%), weekly (10\%), monthly (7\%), never (4\%), twice in a month (5\%) and about every other months $(4 \%)$. When these results examined, it will be seen that most of the employees are communicating with the managers on a daily basis. This situation will support co-operation, problem solving and communication among employees. 


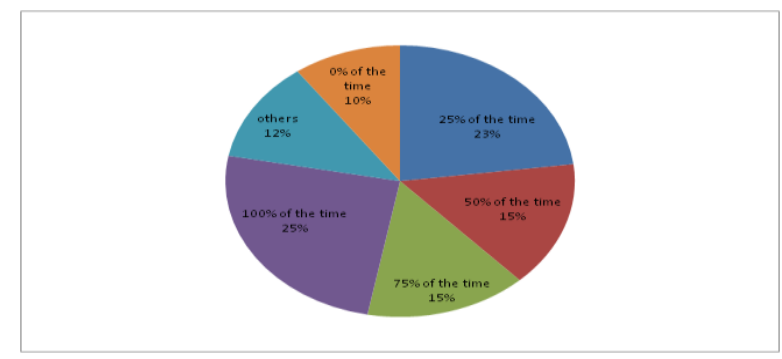

Chart 9 shows a ranking of encouraging employees to do job better: $25 \%$ of managers (all the time), $23 \%$ of managers (25\% of their times), $15 \%$ of managers (75\% of their times), $15 \%$ of managers (50\% of their times), For encouraging employees to do job better much more importance must be given.

"How often does your manager meet you to review your performance objectives?"

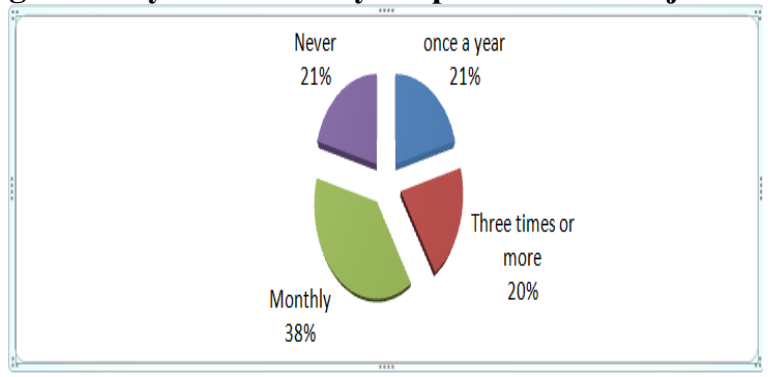

Chart10 shows a ranking of reviewing employee's performance objectives by managers: monthly (38\%), never $(21 \%)$, three times a year and more $(20 \%)$, once a year $(21 \%)$. From these results it can be said that sampled hotels have to be more interested in reviewing employee performance objectives. Because this subject is related with career planning and general performance of the hotels. Informing standards for performance criteria every hotel must evaluate its own structure and activity.

"How often does your manager seek your advice before decision making that can directly affect your job?"

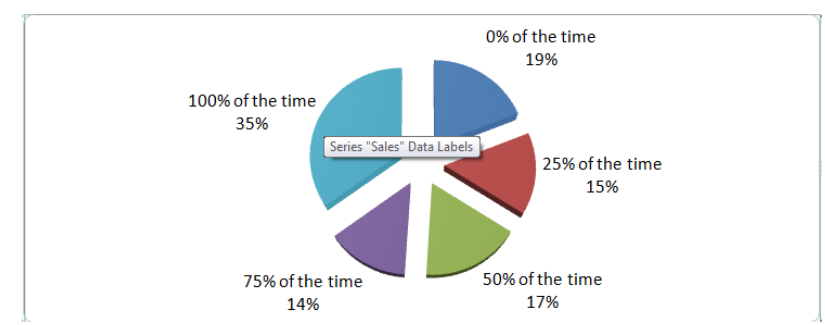

Chart 11 shows a ranking of asking employee ideas by managers making decisions: $35 \%$ of managers (all the time), $17 \%$ of managers (50\% of their times), $14 \%$ of managers ( $75 \%$ of their times), $12 \%$ of managers (25\% of their times).

Generally asking employee ideas before making decisions will increase motivation and give belonging feeling to employees.

"Does your manager gives you feedback about your performance in job hence you can improve future performance?"

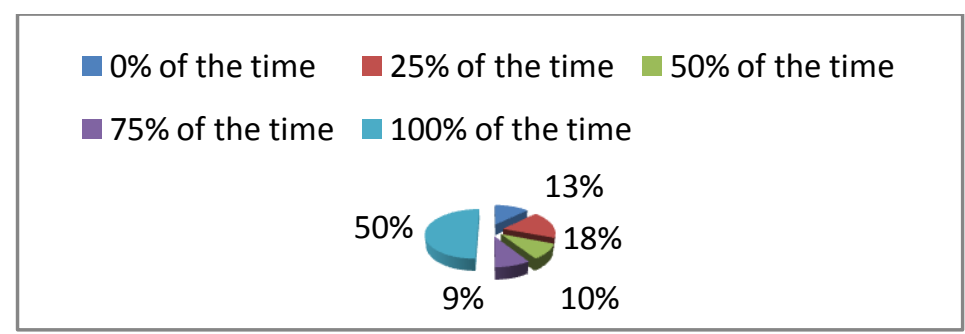


Chart 12 shows a ranking of giving feedback by managers: $50 \%$ of managers (all the time), $18 \%$ of managers ( $25 \%$ of their times), $10 \%$ of managers (50\% of their times), $5 \%$ of managers ( $75 \%$ of their times).

Having information about performance results is important for both managers and employees. Performance results can be helpful for hotels determining deviations between targets and outputs.

"Characterize your interactions with your own department with respect to the given adjectives."

\section{Competitive- Cooperative}

n Competitive $\square$ Co-operative $\square$ Neutral

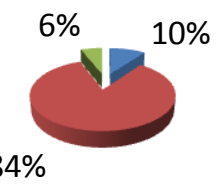

Chart 13 shows a ranking of employee interactions with own department: cooperative (84\%), competitive $(10 \%)$, neutral $(6 \%)$.

Most of the employees evaluate the interactions with their own department as cooperative. This situation will make communication easier.

\section{Informative-Uninformative}

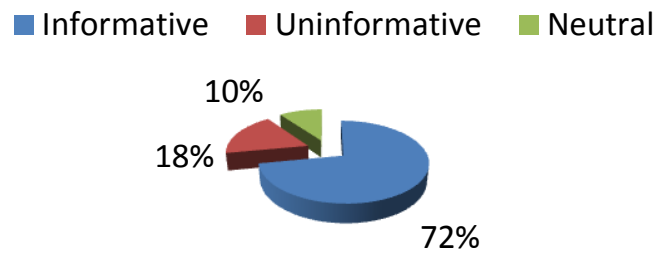

14 Chart 14 shows a ranking of employee interactions with own department: informative (72\%), uninformative $(18 \%)$, neutral $(10 \%)$.

\section{Blaming-Problem Solving}

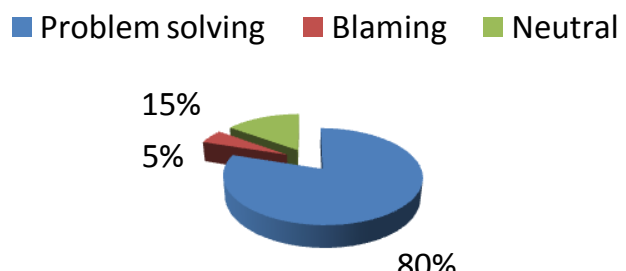

$80 \%$

Chart 15 shows a ranking of employee interactions with own department: problem-solving (80\%), neutral (15\%), blaming (5\%).

Both in graphic 14 and 15 it seems there is no problem in employee interactions related with being informative and problem-solving.

"Characterize your interactions with the employees of other departments with respect to the given adjectives." 


\section{Competitive-Cooperative}

- Cooperative $\square$ Competitive $\square$ Neutral

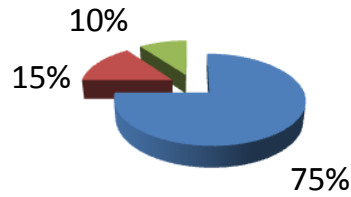

Chart 16 shows a ranking of employee interactions with other departments: cooperative (75\%), neutral (10\%), competitive (15\%).

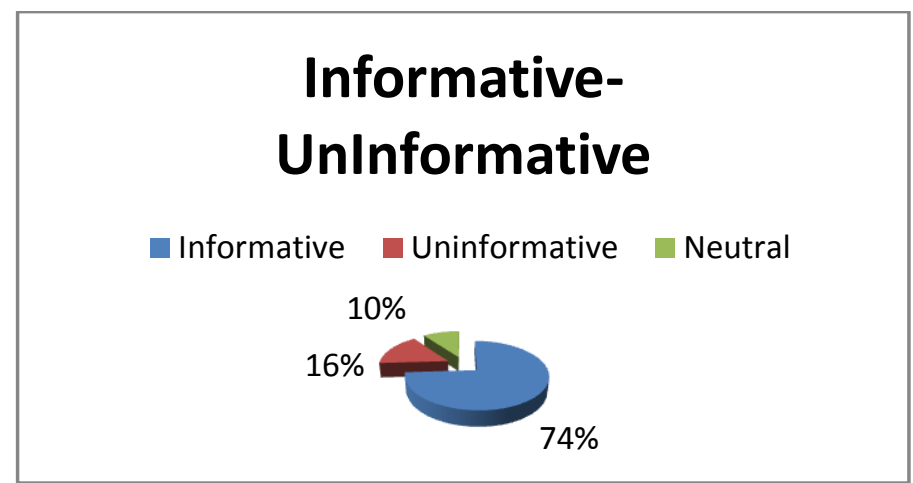

Chart 17 shows a ranking of employee interactions with own department: informative (74\%), neutral (10\%), uninformative (16\%).

\section{Blaming-Problem Solving}

- Problem Solving $\quad$ Blaming $\square$ Neutral

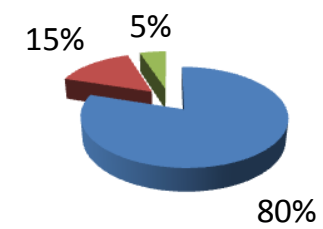

Chart 18 shows a ranking of employee interactions with other departments: problem-solving (80\%), neutral (5\%), blaming (15\%).

Both in graphic 16, 17 and 18, it seems there is no problem according to interactions with other departments in being cooperative, problem-solving and informative.

\section{Analysis Of Hotel Comparisons}

The analysis mentioned before are the combined results of the two four-star hotels. The results show that two sampled hotels have a general tendency to communicate within the same pattern and employ the same types and tools of communication, although some minor variations are observed.

Below mentioned analysis are based on the comparison of the two sampled hotels according to the employee performance objectives, team working, open door policy and usage of the open door policy subjects. 

"How often does your manager meet you in order to review your performance objectives?"

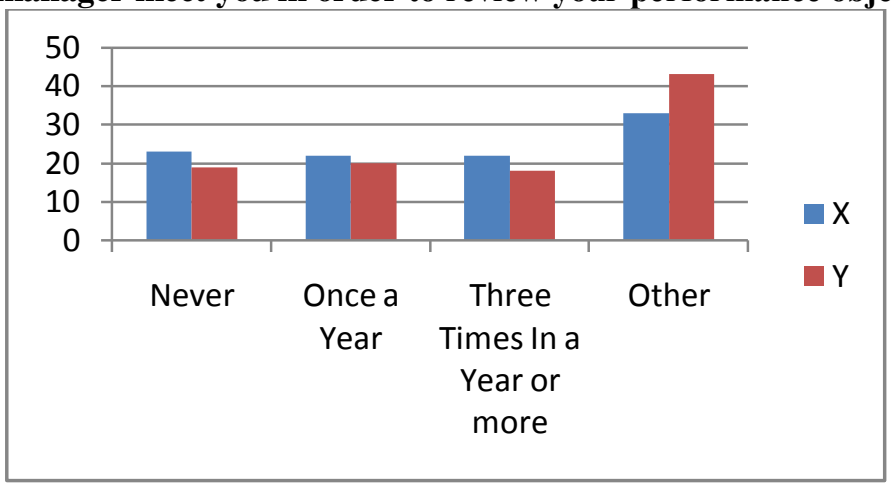

"How often does your manager ask for your ideas before making decisions that affect your job?"

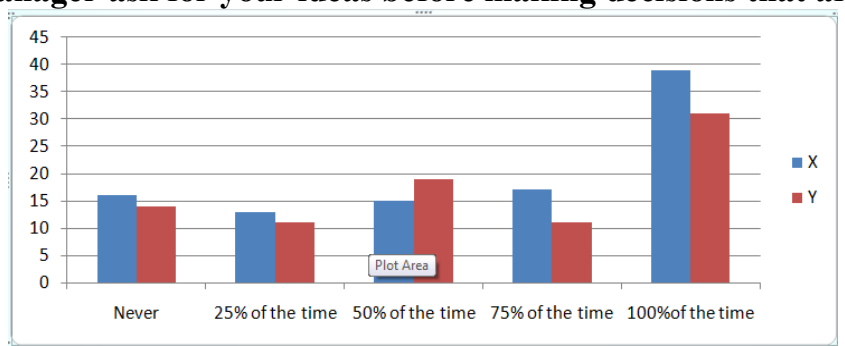

"Does your manager give you enough feedback about the way you perform so that you can improve your job performance?"

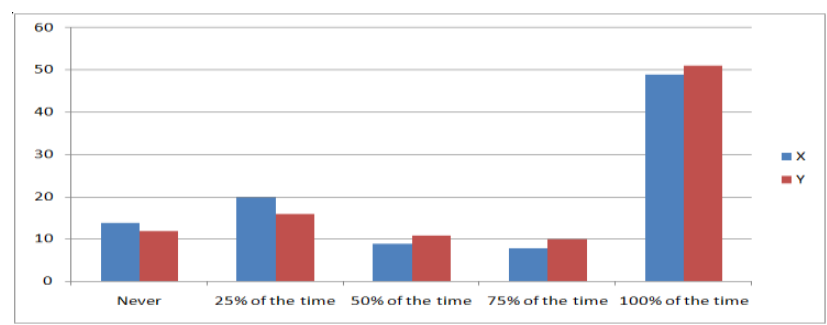

"Are you aware of the Open Door Policy?"

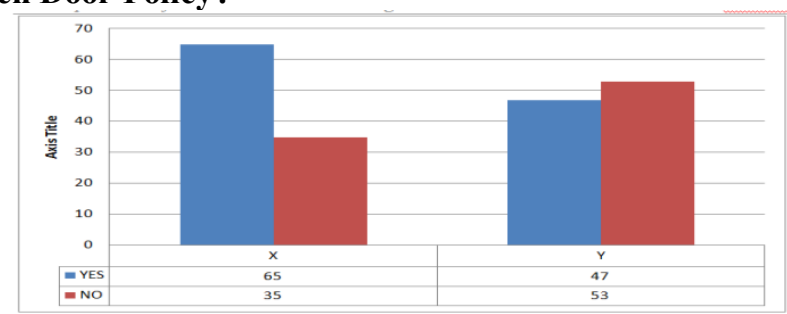

In terms of open door policy, $65 \%$ of the Hotel $\mathrm{X}$ employees states that they are familiar with the open door policy concept as oppose to $35 \%$ of them do not know what it means. On the other hand, $47 \%$ of the Hotel Y employee's states that they are familiar with the open door policy concept as oppose to $53 \%$ of them do not know what it means. This difference can be again attributed to the characteristics of the Hotel $\mathrm{X}$ being a member of a big chain.

"Have you ever used Open Door Policy to take your concern directly to higher management?"

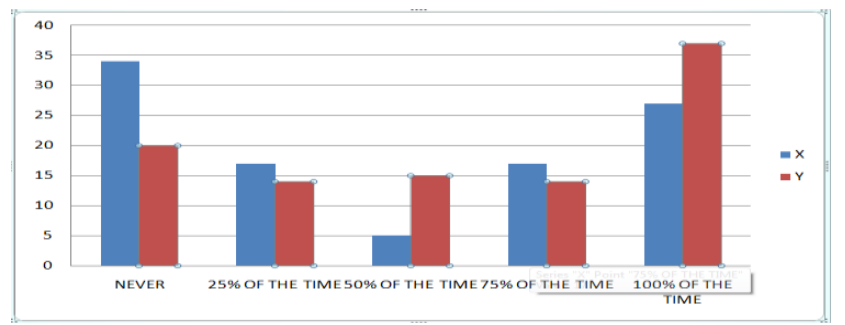

Although as discussed in chart 25, $65 \%$ of the Hotel X employees states that they are familiar with the open 
door policy concept, $27 \%$ of them "100\% of the time" makes use of this as oppose to $37 \%$ of the Hotel Y employees using "100\% of the time". In addition to this argument, $34 \%$ of the Hotel X employees states that they "never" use this approach as oppose to $20 \%$ of the Hotel Y employees. This results show that being a member of a chain and knowing the approaches does not guarantee the usage and performance.

\section{Results and Comments}

1. Memos, Supervisors and Co-workers are the three mostly used information sources as stated by the sample hotels. Employee preferences show a similar preference to Memos and Employee Meetings With top management, Face to Face with supervisors and training possibilities. Equal importance should be given to oral and written communication. In order to increase the effectiveness, much more attention must be given to bulletin boards, hotel newspapers and E-mail connections.

2. The ways of communication within/with other departments show very little change in the order; face to face and telephone/mobile phone possibilities. For communication with other department's sampled hotels prefer memos/note/fax possibilities. For communication within department sample hotels prefer group meetings.

3. According to the research, in the sampled hotels telephone/mobile is the most preferred followed by face to face communication by food \& Beverage, Housekeeping mostly prefer face to face; accounting \& finance mostly prefer telephone/mobile phone; human resources mostly prefer face to face and telephone/ mobile phone; Front Office mostly prefer telephone/mobile phone; Technical Service mostly prefer face to face and telephone/mobile phone.

4. It is found that most of the employees said that they get an opportunity to communicate with their managers daily. This situation enables cooperation, problem solving, mutual understanding, group dynamics and communication among employees.

5. According to the result much more importance should be given to encourage their employees and offer them better job ideas. This will help them to be innovative and will increase their efficiency.

6. Review of the performance objectives of employees by their employers should be given more importance. This will help in increasing motivation, feeling of belongingness, employee loyalty as this play an important role.

7. Most of the employees see their colleagues as informative, problem-solving, cooperative whether in their own department or in other departments.

8. In the sampled hotels most of the employees state that they have accurate and sufficient information from supervisor/managers on time. Communication with management subject plays a critical role in communication.

9. For sampled hotels it can be said that employees have a good cooperation in asking suggestions or providing help to each other. Evaluating data generally, will enable to state the real communication situation of sampled hotels. Sampled hotels have normal levels of formal communication from "down to up" with communication between employees and managers, asking employee ideas before making decisions, but in encouraging employees managers must be more interested. From "up to down" employees accept the current communication situation. For increasing the effectiveness much more importance can be given to written communication like bulletin boards, hotel newspapers. Having sufficient, accurate information is also supporting the current "up to down" communication. From "horizontal" and "cross" communication, employees see their colleagues as informative, problem-solving, cooperative both in their and in other departments.Consequently, it can be said that sampled hotels have a normal formal communication with sufficient information flows supporting "up to down", "down to up", "horizontal" and "cross" communications. As a whole they have the possibility to complete their communication policy with their corporate policy. 